\title{
A Research on Satisfaction during Friday Religious Services, Practices Associated with Health and Social Relationships, in Anadolchioi Mosque
}

\author{
Feiza Memet
}

\section{ABSTRACT}

This paper evaluates the indoor temperature and thermal sensation inside the naturally ventilated small-medium size, historical Anadolchioi Mosque, built in Constanta, in 1870, for the Muslim minority living in Constanta. Are considered Friday prayers (Dhuhr). The methodology used for this assessment is related to the outdoor and indoor temperatures measurements, each Friday, in July, between 10 AM and 4 PM, due to the fact that in Constanta, Friday prayers (in July) starts between 1.20 PM and 1.23 PM (depending on the sun position). The measurements will indicate that, although indoor temperature is slightly higher than the outdoor one, the average indoor temperature, for the considered period, is in the recommended thermal comfort temperature range, according to ASHRAE 2010. Also, the measured indoor air temperatures and predicted temperature for comfortable indoors- given by Humphreys formula, have been compared, in order to have an idea if the building is able to provide pleasant indoor temperatures. On the other hand, the methodology is focusing on ASHRAE seven point scale, when assessing the thermal sensation. In this respect, a survey regarding the thermal sensation of the occupants indicated that a low percent $(5.55 \%)$ felt uncomfortable during the religious services. The majority of occupants $(\mathbf{7 7 . 7 7 \%})$ felt comfortable and do not need a cooler environment. The results are in concordance with the participants' age profiles: older persons preferring higher indoor temperatures.

Keywords: historical mosque, sensation, temperature.

Published Online: June 19, 2021

ISSN: $2736-5514$

DOI: $10.24018 /$ theology.2021.1.3.16
F. Memet*
General Engineering Sciences
Department, Constanta Maritime University, Romania.
(e-mail: feizamemet@yahoo.com)

*Corresponding Author

\section{INTRODUCTION}

Ensuring satisfaction during religious services has a social aspect due to the fact that it is connected with the public health of a community.

Mosque is the religious building, where Muslims gather for praise and worship. This is a building with intermittent schedule, in accordance with local prayer hours as in [1].

Prayer is one of the most important Five Pillars of Islam; for this reason, Muslims perform throughout the day five prayers and weekly - Friday prayers.

Although Muslims are expected to pray five times daily, they can fulfil their obligation by attending the Mosque, or from any other location - such as homes.

Muslims pray facing Mecca at times given by the position of the sun; thus, prayer times are as follows: Mahgrib (at sunset), Isha (in the evening), Fajr (at dawn), Zuhr (at noon) and Ash (in the afternoon) as in [2].

The most important prayer within a week is the Friday prayer, called Dhuhr, since, in Islam, Friday is the day chosen by Allah as the day of worship.
In this respect, it is expected that Muslim men attend the mosque for the Friday prayers, while attendance of women is optional. Dhuhr occurs at midday.

The religious ritual involves praying during standing, bowing, prostrating and sitting, during which believers stay in straight and parallel rows.

Between rows are approximately $1.2 \mathrm{~m}$ as in [3]

Their activity is a light one and takes about 15 minutes, normally.

As required, muslims attend the prayer service in modest, clean, and nice clothes; they wear loose fitting clothes, long sleeves, socks and headscarfs, the overall average clothing insulation value appropriate to be considered being $0.53 \mathrm{clo}$, found considering the clothes assembles references from ISO -7730 (2005) as in [4], [5], [6].

In mosques, gender segregation is mandatory during religious events, so that men occupy the main prayer room, while for females are allocated ladies galleries as in [7].

Thermal comfort in mosques is connected to occupant's wellbeing in this space, where people should find comfort, peace and serenity, in accordance with their clothing and activities. 
Some studies are indicating that thermal comfort in mosques cannot be associated with ISO 7730 and ASHRAE $55-2004$ as in [8], [9], [10].

Many of historic mosques are still not equipped with $\mathrm{AC}$ systems, a real concern being related to the comfort of believers, based on natural ventilation in these spaces.

In these conditions, the interest it is focused on outdoor climatic conditions as in [11].

This study investigates the indoor temperatures that ensure a pleasant environment to the users, inside the historical, naturally ventilated Anadolchioi Mosque from Constanta, Romania, and the thermal sensation of the participants based on indoor and outdoor temperatures measurement and recording and on the thermal sensation of participantsreflected in their votes, based on ASHRAE seven point scale.

The study was developed during Friday prayers, taking place in the month of July 2020.

Thus, the methodology consists in analyzing the outdoor and indoor air temperatures for four Fridays, in the comparison between the measured indoor air temperatures and the indoor predicted comfort temperature, given by Humphreys' formula, while the thermal sensation results by the use of a survey, asking directly if worshippers need changes in their space.

\section{METHODS}

The selected historical Anadolchioi Mosque from Constanta was built in 1870 .

Previously, Anadolchioi was a village with an important Turk and Tartar community. Since 1975, Anadolchioi is a part of Constanta, the mosque being now surrounded by residential blocks.

The main prayer space has a square form. Inside dimensions of the mosque are length: $11 \mathrm{~m}$, width: $7 \mathrm{~m}$ and height: $6 \mathrm{~m}$.

It is covered by a semi spherical dome, supported by a band of triangular planes.

The load bearing masonry walls are made by stone - on the lower portion. The upper side is an alternation of stones and bricks.

There is also a brick minaret with a stone base, located at the southwest corner of the building.

The natural light and ventilation are ensured by six windows, rising to the upper level of the walls and two windows at the balcony.

The mosque can be considered as a medium to small size mosque.

Because of COVID-19 pandemic, in Romania are allowed inside prayers starting with 17 June 2020, with keeping a distance of $2 \mathrm{~m}$, in any directions, between participants.

In the above mentioned period of the year, in Constanta, Friday prayer (Dhuhr) starts between 1.20 PM and 1.23 PM.

During the four Friday prayers in July 2020, the participants were all males.

It was observed that attended 18 persons (imam included), the same in all four days.

Their age profile is as follows: 2 in the age range of 30-40, 2 in the age range 40-50, 5 in the age range of 60-70, 3 in the age range of 70-80 and 6 in the age range of 80-90.

Air temperature measurements have been possible by the use of TESTO- 435-2 equipment, a tool able to measure parameters such as temperature, relative humidity or velocity.
Since this study focuses on indoor and outdoor air temperatures, were used only the records regarding this parameter.

The accuracy of the equipment when measuring and recording the air temperature is $\pm 0.2{ }^{\circ} \mathrm{C}$.

The measurement equipment was tested.

The measurements were done between 10.00 and 16.00, at $1.0 \mathrm{~m}$ from the ground floor, every minute, as indicated in ASHRAE 2010, in the main prayer room.

\section{RESUlTS AND DISCUSSION}

The average outdoor and indoor air temperatures for the four Fridays in July 2020 are given in Fig. 1, where $t_{e}-$ the average outdoor temperature and $t_{i}-$ the average indoor temperature.

It was seen that the difference between this two temperatures is in the range $(0.5 \div 2){ }^{\circ} \mathrm{C}$, for the monitored period; also, the indoor temperature is slightly higher than the outdoor one.

The most important temperature difference it is registered at $3 \mathrm{PM}$. According to considered standard, the recommended thermal comfort temperature is in the range $(22 \div 26){ }^{\circ} \mathrm{C}$.

In this respect, results that indoor temperature level is appropriate for pleasant indoor climate inside the mosque, between $10 \mathrm{PM}$ and $2 \mathrm{AM}$, during the considered period, as seen from the figure below.

Having in view that Friday prayer, during July, takes place at about 1 PM, the historical Anadolchioi Mosque ensures appropriate indoor temperatures for its occupants, throughout natural ventilation.

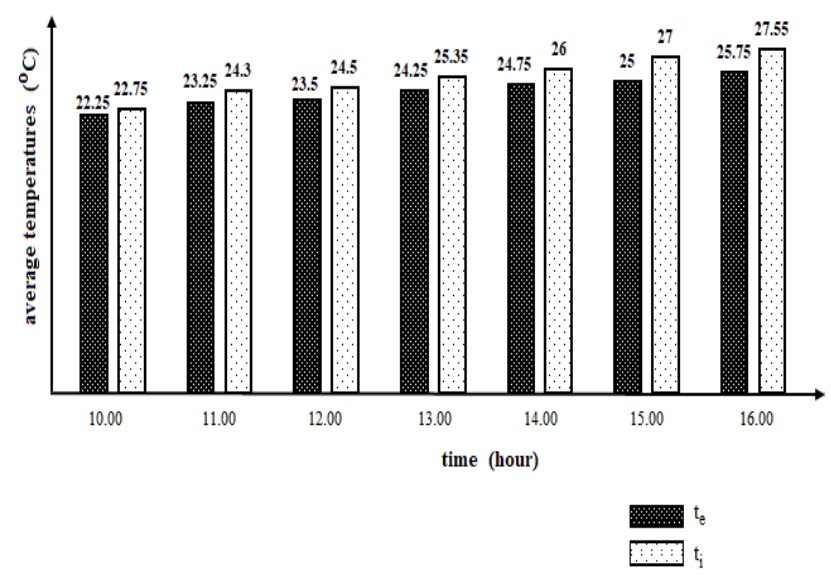

Fig. 1. Differences between average outdoor and indoor temperatures for Fridays in July 2020.

The environmental performance of the mosque, from the indoor temperature perspective, can be also evaluated by the comparison between the measured indoor air temperatures $\left(\mathrm{t}_{\mathrm{i}}\right)$ and the predicted temperatures for comfortable indoors $\left(t_{p}\right)$, by the use of Humphrey's formula as in [12]:

$$
t_{p}=0.53 t_{m o}+13.8
$$

where: $t_{m o}-$ mean outdoor temperature for each month.

In the above given formula, temperatures are introduced into Celsius degrees.

Due to the fact that our study takes place in July, it was found that the mean outdoor temperature for July is $21^{\circ} \mathrm{C}$. 
Results that the indoor predicted thermal comfort temperature is $24.93{ }^{\circ} \mathrm{C}$.

By comparing this value with ones of the indoor temperatures, as given in Figure 1, can be observed that till 1 PM the building is able to provide a pleasant indoor climate.

This comparison is useful when it is aimed to found if indoor temperatures should be modified in order to meet the participant's needs.

For a mosque, this is very important, since occupants cannot adapt their cloths or activity to the indoor temperatures.

Further, a survey that will reveal the thermal sensation of participants is useful, in order to identify the satisfaction of occupants, in natural ventilation conditions.

Thus, a questionnaire was distributed to all the participants, after each Friday prayer, being asked to select only one option from the thermal sensation scale.

The seven points met on the thermal sensation scale were explained to the participants:

$$
\begin{aligned}
& \text {-3: cold, } \\
& \text {-2: cool, } \\
& \text {-1: slightly cool, } \\
& \text { 0: neutral, } \\
& \text { +1: slightly warm, } \\
& \text { +2: warm, } \\
& \text { +3: hot. }
\end{aligned}
$$

In terms of comfort, the scale reveals:

-3 : very uncomfortable,

-2: uncomfortable,

-1: slightly uncomfortable,

0 : comfortable,

+1 : slightly uncomfortable,

+2: uncomfortable,

+3 : very uncomfortable.

The responses are given in Fig. 2.

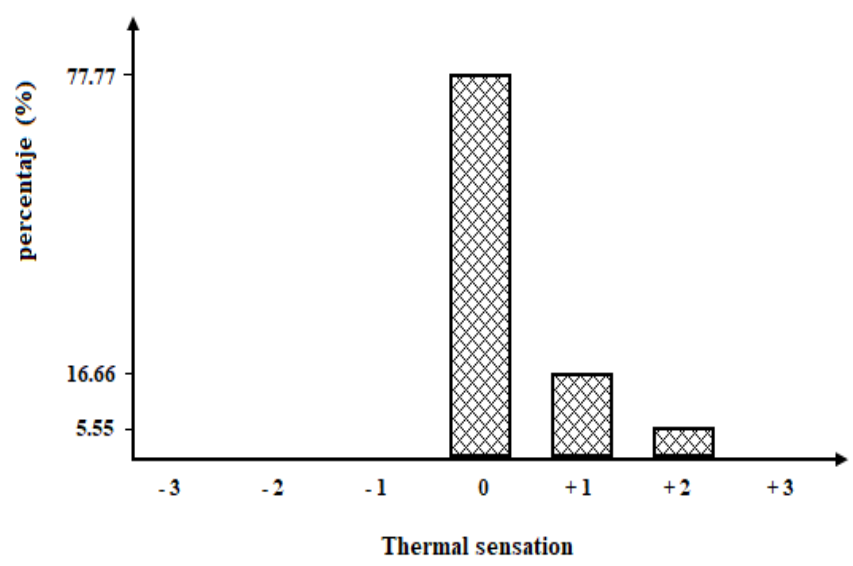

Fig. 2. Responses on thermal sensation

The majority of occupants voted for a comfortable sensation, less votes reflect an uncomfortable sensation $(5.55 \%)$, indicating a low need for a cooler climate.

It is about the vote of the younger participants.

This might be explained by the fact that the thermal sensation is different among adults, older adults preferring higher indoor temperatures, since the aging process influences the perception of thermal comfort as in [13].
The adaptation to the indoor temperatures is easier, due to the fact that there is no significant difference between indoor and outdoor temperatures.

Moreover, has not been noticed fast condition changes during the monitored period, meaning that the mosque building is able to ensure thermal stability.

\section{CONCLUSION}

The aim of this study was to assess capacity of the historical, naturally ventilated Anadolochioi Mosque, from Constanta, to ensure a pleasant indoor temperature to the occupants during prayers.

The subject was Friday prayers taking place in July 2020.

The study revealed that during the four Fridays attended males most of them being over $60(77.77 \%)$.

Measurements focused on outdoor and indoor temperatures, between 10.00 AM and $4 \mathrm{PM}$, even if the Friday prayer takes place at about $1 \mathrm{PM}$.

In this time range, indoor temperature was slightly higher than the outdoor one (the most important temperature difference being noticed at 3 PM: $2{ }^{\circ} \mathrm{C}$ ).

During the four Friday prayers in July, the indoor average temperature was $25.35{ }^{\circ} \mathrm{C}$ which, according to ASHRAE 2010 , is in the recommended thermal comfort range.

The estimation of the indoor predicted comfort temperature, by the help of Humphreys' formula, is useful when discussing about pleasant indoor temperatures.

The measured indoor temperatures resulted to be lower than the calculated indoor predicted comfort temperatures in the morning hours till the Friday prayer hour, meaning that the building is able to ensure a pleasant indoor temperature to its occupants, throughout natural ventilation.

Additionally, a survey on the thermal sensation of the participants showed that the majority felt comfortable $(77.77 \%)$, while $16.66 \%$ felt slightly uncomfortable and only $5.55 \%$ felt uncomfortable during the religious services.

The picture of the thermal sensation is rational, since people over 60 require higher indoor temperature, because their loss in the ability to regulate body temperature.

\section{REFERENCES}

[1] A. B. Atmaca and G. Z. Gedik, "Evaluation of mosques in terms of thermal comfort and energy consumption in a temperate- humid climate", Energy and Building, vol 195, pp 195-204, 2019.

[2] G. Sarwar, Islam-Faith and Teachings, 3rd Ed Timişoara, Romania: Vanessa, Asociaţia Studenţilor Musulmani din România, 1998, pp 20 30 .

[3] A. A. A. Shohan and M. B Gadi, "Evaluation of thermal and energy performance in mosque buildings for current situation (simulation study) in mountainous climate of Abha City", Sustainability, vol 12, no 10, pp 1-37, 2020.

[4] S. Shodiya, M. Ben Oumarou, G. Ngala, A. Muhammed and M. Yusuf, "Thermal comfort in naturally ventilated large space building in Maiduguri, Borno State", ATBU, Journal of Science, Technology \& Education (JOSTE), vol 4, no 1, pp 16-24, 2016.

[5] G. Calis, B. Alt and M. Kuru, "Thermal Comfort and Occupan satisfaction of a Mosque in a Hot and Humid Climate", in The 2015 International Workshop in Civil Engineering, Ed. William J. O’Brien, Simone Ponticelli, Austin, 2015, pp 139-147.

[6] F. F. Al-ajmi, A. S. Al-azmi and F. A. Alrashidi, "Indoor environmental quality in air- conditioned mosque buildings in Kuwait", American Journal of Civil Engineering and Architecture, vol 5, no 4, pp 167-173, 2017.

[7] L. Nyhagen, "Mosques as gendered spaces: the complexity of women's compliance with, and resistance to, dominant gender norms, and the importance of male allies", Religions, Vol 10, no 5, pp 1-15, 2019. 
[8] F. F. Al-Ajmi, "Thermal comfort in air-conditioned mosques in the dry desert climate, Building and Environment, vol 45, no 3, pp 704-710, 2010.

[9] F. S. Sezer and E. Kaymaz, "The user's perception of indoor comfort conditions in historical mosques: the case of Bursa, Turkey", International Journal of Humanities and Social Science, vol 6, no 9, pp 43-45, 2016

[10] S. S. Ibrahim, A. Baharun, M. N. M. Nawi and E. Junaidi, "Assesment of thermal comfort in the mosque of Sarawak, Malaysia", International Journal of Energy and Environment, vol 5, no 3, pp 327-334, 2014.

[11] K. S.M. Bughrara, Z. D. Arsan and G. G. Akkurt, "Effect of intervention strategies on seasonal thermal comfort conditions in a historic mosque in the Mediterranean climate", in The $3^{\text {rd }}$ International Conference on Energy Efficiency in Historic Buildings (EEHB 2018), ed. Swedish Energy Agency, Uppsala University and the Swedish National Heritage Board., Visby, 2018, pp 363-371.

[12] A. Gallardo, M. Palme, A. Lobato-Cordero, R.D. Beltran and G Gaona, "Evaluating thermal comfort in a naturally conditioned office in a temperate climate zone", Buildings, vol 6, no 3, pp 1-20, 2016.

[13] R.L. Hwang and C.-P. Chen, "Field study on behaviours and adaptation of elderly people and their thermal comfort requirements in residential environments", Indoor Air, vol 20, no 3, pp 235- 245, 2010.

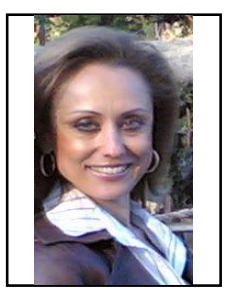

Feiza Memet date of birth: 25 November 1967 , place of birth Medgidia/ Romania, educational background: 1987- 1992 Bachelor of Science Degree from Technical University of Constructions, Bucharest, Romania, 1996- 2000 Ph.D Degree in Mechanical Engineering from Technical University of Constructions, Bucharest, Romania, 2000-2002 Master Degree in Maritime and Harbor Management from Constanta Maritime University, Romania. Author's major fields are thermodynamics and marine refrigeration.

She has experience in teaching, research and management activities in Constanta Maritime University, Romania. In 2009, she started her work in Constanta Maritime University as an ASSISTANT. In the present time she is ASSOC.PROF. in the same university. Between 2004- 2009 she was VICE DEAN OF MARINE ENGINEERING FACULTY FROM CONSTANTA MARITIME UNIVERSITY, while since 2009 till now she is CHEAF PART TIME STUDIES DEPARTMENT. She is the author of more than 80 papers, among which: F.Memet, "Aspects to be known by marine carriers involved in halal food chain", European Journal of science and Theology, vol 15, no 3, pp 79-83, June 2019, F.Memet, " Is there any link between beliefs and environmental issues within a green energy cluster?", European Journal of science and Theology, vol 13, issue 1, pp 111-116, 2017, F.Memet, "A performance analysis on a vapor compression refrigeration system generated by the replacement of R 134a", Journal of maritime Research, vol 11, no 3, pp 83-87, December 2014.

Assoc. Prof. Dr. Memet is member in different professional association, among them being ModTech Association. 